\title{
Medication Therapy Management Favors Large Pharmacy Chains and Creates Potential Conflicts of Interest
}

\author{
Daniel M. Cook, PhD, and Adel Mburia-Mwalili, MEd, MPH
}

W e hypothesize that recent changes in policy and the spread of in-store medical clinics favor the provision of medication therapy management (MTM) services by large chain pharmacies while creating the potential for conflicts of interest from employed prescribers. First, MTM is now required by Medicare Part $\mathrm{D}$, but the program may be more practical for community pharmacy chains than independent pharmacies. Second, in-store clinics have proliferated, which may accommodate the provision of MTM services in these community locations. Third, while physician ownership of pharmacies is restricted, the law has not anticipated the in-store clinic situations in which the pharmacy employs a prescriber on-site.

\section{MTM Required Under Medicare Part D}

In an important policy shift, pharmacists can now seek reimbursement for cognitive clinical consulting services from plans that contract with the Centers for Medicare \& Medicaid Services (CMS) to provide Medicare Part D benefits. ${ }^{1,2}$ This change is the outcome of 2 major laws. The Medicare Prescription Drug, Improvement, and Modernization Act of 2003 (MMA 2003) mandated that Part D Prescription Drug Plans (PDPs) or Medicare Advantage Plans (MA-PDs) provide MTM services using pharmacists "or other qualified healthcare providers."3 Earlier, the Health Insurance Portability and Accountability Act of 1996 included pharmacy and all health professions in the definition of health data transmission, which inspired the formation of a pharmacy coalition to lobby for billing codes for professional services. ${ }^{4}$ The billing codes for MTM services were implemented in 2006. CMS monitors the PDPs, but less is known about the details of service delivery to patients in the community. One recently published study in JMCP made use of private-sector data for 7 years of MTM services, within and without Part D, and suggested that MMA 2003 inspired the type of MTM services to move from education involving acute medications to consultative services for chronic therapy, with attributable cost avoidance. ${ }^{5}$

\section{Definition of MTM}

After the passage of MMA 2003, 11 national pharmacy organizations participated in a process to arrive at a consensus definition of MTM for the purposes of policy and rule making before the MTM billing codes were published. ${ }^{6}$ According to this definition, MTM includes a wide range of professional activities and responsibilities, such as (a) assessment of the patient's health status; (b) formulation of a medication treatment plan; (c) monitoring and evaluation of the therapy; (d) medication review to identify, resolve, and prevent medication-related problems; (e) recording of care delivered and communication with the patient's other primary care providers; (f) providing verbal education and training to the patient to promote appropriate medication use; and (g) providing information, support, and resources that enhance adherence to medications. ${ }^{6}$ In general, MTM services are intended to promote patient understanding about medication use, increase adherence to drug regimens, and detect drug-related problems. Studies of MTM interventions, such as the Asheville project and others, have demonstrated that MTM can effectively increase safety and reduce health care costs, decrease hospitalizations and lost work days, ${ }^{7}$ improve access to drugs, and reduce out-of-pocket costs. ${ }^{8}$ The evidence of the effects of clinical pharmacy interventions on health and on costs is mixed, with evidence demonstrating positive health outcomes ${ }^{9}$ but less evidence for medical cost savings or refill adherence. ${ }^{10,11}$ Results may be difficult to demonstrate because comprehensive MTM reviews require the cooperation of a physician or other prescriber in order to fully complete the health-medication intervention, although compliance issues can be resolved directly with the patient.

The American Medical Association Current Procedural Terminology (CPT) panel created 3 temporary CPT codes (0115T, 0116T, 0117T) for pharmacists and pharmacies providing face-toface MTM services. ${ }^{12}$ These CPT codes, which became effective on January 1, 2006, allowed pharmacists to bill third-party payers for MTM services. On January 1, 2008, after only 2 years of use, the temporary codes were made permanent as CPT codes 99605, 99606, and 99607. ${ }^{13}$ The 99605 code is for a new patient, and 99606 is for a follow-up visit. These 2 codes are used for the first 15 minutes of time spent with a patient. If the visit extends for more than 15 minutes, then the code 99607 is used for each additional 15 minutes spent with the patient. ${ }^{13}$ Ostensibly, the pharmacist billing codes focus on the length of time spent in face-to-face contact with the patient and do not take into account the clinical complexity of the patient, unlike CPT codes used by physicians. ${ }^{14}$

Medicare Part D MTM services are administered by the private PDPs and MA-PDs. Therefore, data from the billing codes will be held at the discretion of the private sector because MTM services are required for the contracts and are not billed to Medicare directly but, rather, are considered with administrative costs in the original bid. At present, the CPT codes will not provide an available source of government data on utilization of services 
by individual beneficiaries, although researchers with access to private data may choose to publish studies in the literature. Sponsors submit details to CMS in annual reviews but without separate tracking for MTM services.

Pharmacists are now able to obtain the National Provider Identification (NPI) number in order to seek reimbursement for services, although many pharmacists will continue to deal directly with plan sponsors and not with CMS. ${ }^{15}$ The MMA 2003 created the first reason for pharmacists to obtain an NPI; providers with an NPI, which is required by some but not all PDPs, are better able to contract with PDPs and bill for MTM. ${ }^{15}$ The list of providers with an NPI is searchable online at the National Plan and Provider Enumeration System (NPPES) website, https:// nppes.cms.hhs.gov/NPPES/NPIRegistryHome.do. While pharmacists are identified as such, the NPI numbers cannot be sorted by profession.

Because the NPPES is a large dataset, we searched a small state for individual pharmacists with an NPI in May 2008. Our own state of Nevada has 2.5 million residents and about 2,000 licensed pharmacists and contains a large, fast-growing southwestern city in Las Vegas. We found that Nevada had at least 133 individual pharmacist health care providers that have obtained NPI numbers. Most of these, 110 (83\%), are in Clark County, which contains Las Vegas and most of the state's population. The NPI list included 61 providers with a doctor of pharmacy degree, 41 registered pharmacists, and 31 with other credentials, including students, science degrees, and none. The NPPES system indicated that 19 Nevada zip codes had more than 150 records (all providers), but a maximum of 150 records were displayed in search results, so the presence of additional providers in these areas (mostly in Las Vegas) is likely, but unknown.

\section{Part D MTM Providers: Suitable for Chain Stores}

Although utilization data are not freely available in the public sector, more details are known about the contracted PDPs and enrollment. In 2006, 20.7 million people were enrolled in Part D plans. ${ }^{16}$ In that year, a survey of insurance plans about MTM programs received responses from 70 companies operating 50 PDPs and 221 MA-PDs that represented 12.1 million enrollees in 21 distinct MTM programs. ${ }^{16}$ For contract year 2008, CMS announced that there were 712 active Part D contracts with approved MTM programs, 609 MA-PD, and 103 PDP. ${ }^{17}$ These plans had various characteristics and rules, including the type of services provided and the eligibility requirements, all within the legal guidelines. A wide range of services was provided, including mailed information, telephone consultations, and in-person appointments. Eligibility requirements varied considerably, with 90.5\% restricting enrollment based on number of disease states (median 3, range 2-5), 57.1\% requiring a specific chronic condition, and $95.2 \%$ requiring a certain number of medications (median 6, range 2-24). ${ }^{16}$ According to CMS, algorithms are commonly used to identify beneficiaries for services that include reminders, letters, newsletters, and screenings- $43 \%$ of MTM programs in 2008 used monthly algorithms, and $40 \%$ used quarterly algorithms. ${ }^{17}$

Sponsor plans may or may not utilize community pharmacies for delivering services. The survey of plans found millions of enrollees, yet the actual amount of service provided was not enumerated in the report, and enrollees do not necessarily take advantage of MTM review opportunities. ${ }^{18}$ In addition, which health care professionals are providing which services is not clear. According to CMS, nearly one-half of plans in 2008 reported using in-house staff only for MTM services, whereas $28 \%$ used outside personnel, and $23 \%$ used a combination. ${ }^{17}$ Whether using in-house staff or outside contractors, 98.2\% of PDPs and MA-PDs make use of pharmacists, whereas some Part D plans also use physicians (40.4\%), nurses (50.7\%), and other providers (32.4\%) to deliver MTM services. ${ }^{17}$

Pharmacists serving eligible patients in several plans, especially consultant pharmacists and those in independent community pharmacies, may encounter challenges in seeking reimbursement sufficient to cover costs. ${ }^{19-21}$ One report of a pilot project to provide telephonic MTM services concluded from the experience that "key components in MTM development and implementation include a dedicated clinical pharmacist, adequate documentation systems, and administrative support." ${ }^{19}$ Therefore, possible barriers to utilization include high costs of providing services that are sometimes labor intensive, costs of acquiring new administrative capacity, and lack of training or an inability to provide the services. A small consultant pharmacy group that conducts MTM reviews at nursing homes under Medicare, for example, would have many challenges providing this service under Part $\mathrm{D}$ because of additional administrative personnel and, possibly, new information technology requirements to contract with and bill PDPs.

While implementing a new program is challenging to any existing operation, we argue that Part D arrangements are more practical for large chain community pharmacies that have infrastructure in place because of 3 obstacles: low reimbursement rates, additional billing systems, and need for clinical space and training. First, the reimbursement rate may be based on the facetime with patients, and an informal survey conducted by the Lewin Group found that the rate may be as low as $\$ 1$ to $\$ 2$ per minute, or approximately $\$ 75$ to $\$ 120$ for initial visits and $\$ 35$ to $\$ 60$ for follow-up visits. ${ }^{14}$ These rates are not sufficient to encourage and support the provision of MTM services, which are probably more feasible at a starting rate of $\$ 2$ to $\$ 3$ per minute. ${ }^{14}$ In contrast, the state of Minnesota has more satisfactory reimbursement for pharmacists providing MTM under Medicaid using a 5-step pay-scale that is not based solely on face-time but employs a more complicated formula that better includes a pharmacist's expenses, such as number of therapy problems and time spent after the patient visit. ${ }^{20}$ A telephone-based MTM pilot project found that thorough reviews required 90 minutes each. ${ }^{19}$ 
Second, many pharmacists do not have systems in place for billing plan sponsors. Depending on the plan sponsor, they may need to purchase software, obtain the NPI number, hire extra personnel, and submit forms correctly. ${ }^{21}$ Pharmacists will need to become familiar with specific billing key words and use the correct terminology in order not to have claims rejected. ${ }^{22}$ Third, some pharmacists do not feel prepared for consulting; many pharmacists need more training in MTM itself and may not have the space to conduct private consults. ${ }^{23-26}$ Many pharmacists are unfamiliar with billing as service providers, and most have not often been exposed to this concept in formal education or training. ${ }^{24,25}$ We suggest that these 3 obstacles make Part D MTM more attractive to large businesses, particularly if they have instore clinical space and an existing billing infrastructure.

An option for independent pharmacists is to join a network that provides administrative services, such as Outcomes Pharmaceutical Health Care which administers MTM programs nationwide. ${ }^{5}$ This enterprise started in Iowa in 1999 and assists with billing Medicare, insurance plans, and other payers who recognize the economic value of preventing medication errors and complications by providing MTM services. The company processed about 100,000 claims for MTM services in the 7 years from 2000 to 2006..$^{5}$ In April 2009, the company website, http:// www.getoutcomes.com/aspx/consumers/pharmacistfinder.aspx, listed 10,206 MTM locations, or "MTM Centers" in the United States and the District of Columbia, Puerto Rico, and the Virgin Islands. The website also lists locations for service in Canada and Central America. The state with the most Outcomes MTM Centers on this list was Florida $(1,456)$, and high numbers were reported for Georgia (627) and North Carolina (590). These locations are often large chain pharmacies and grocery stores, such as at Walgreens, Rite Aid, Kroger, Safeway, and Medicine Shoppe. Many Outcomes network providers that have undergone baseline training in MTM documentation and billing appear to be large chain community pharmacies, which suggests that large chain pharmacies have quickly prepared to deliver MTM services in response to the MTM opportunities available.

\section{Role of In-Store Clinics in the Provision of MTM}

While independent community pharmacists may not be particularly encouraged by the development of recent Medicare programs, ${ }^{26,27,28}$ larger community chain pharmacies appear to have an advantage in addition to larger scale. Informal discussions with local certified geriatric pharmacists suggested that a potential vehicle for Part D MTM delivery that would not face the same barriers encountered by independent pharmacies is the chain pharmacy in combination with the new in-store medical clinics. The 2006 survey of MA-PDs and PDPs found that $19 \%$ of plans, covering approximately 7.5 million enrollees, contracted out to community pharmacies for MTM services. ${ }^{16}$ An in-store clinic, also called a convenience care clinic, fits well with this MTM contracting model because it is usually a struc-
TABLE 1) Number of In-Store Clinics for Leading U.S. Pharmacy Chains in February 2009

\begin{tabular}{l|l|c|c}
\hline Pharmacy Store & \multicolumn{1}{|c|}{ Clinic Name } & $\begin{array}{c}\text { Number of } \\
\text { Locations }\end{array}$ & $\begin{array}{c}\text { Number of } \\
\text { States }\end{array}$ \\
\hline CVS & Minute Clinic & 545 & 24 \\
\hline Walgreens & Take Care Health Clinics & 326 & 18 \\
\hline Target & Target Clinic & 28 & 2 \\
\hline Wal-Mart & Quickcare & 27 & 6 \\
\hline HEB & RediClinics & 17 & 1 \\
\hline Medicine Shoppe & Corner Care Clinics & 14 & 5 \\
\hline Kroger & The Little Clinic & 6 & 2 \\
\hline Publix & The Little Clinic & 5 & 1 \\
\hline Longs & Quick Health & 3 & 2 \\
\hline Duane Reade & Walk-in Medical Care & 2 & 1 \\
\hline Rite Aid & none & 0 & 0 \\
\hline Albertsons & none & 0 & 0 \\
\hline Brooks-Eckerd & none (now Rite Aid) & 0 & 0 \\
\hline Safeway & none & 0 & 0 \\
\hline Ahold USA & none & 0 & 0 \\
\hline Sears/Kmart & none & 0 & 0 \\
\hline Costco & none & 0 & 0 \\
\hline Winn-Dixie & none & 973 & 0 \\
\hline TOTAL & - & -
\end{tabular}

aSource: Drug Store News, August 22, 2005. ${ }^{35}$ Using this list of top chains, company websites of each chain were searched for information about numbers of in-store health clinics.

ture carved out of the store that provides "one-stop shopping" for health care. ${ }^{29}$ Typically staffed by licensed nurse practitioners and registered nurses, these clinics provide limited primary care services that are quick, inexpensive, and convenient to insured, underinsured, and uninsured individuals. ${ }^{30}$ Patients can have simple medical conditions diagnosed and prescriptions written and filled quickly. ${ }^{29,31}$ In theory, a pharmacist could see MTM clients in the clinical space, or MTM could be provided by another professional. Thus, this new in-store medical clinic model seems to be in a position to surmount barriers to offering MTM under Medicare. The clinics have low operational costs, appropriate space, and billing infrastructure. ${ }^{32}$ The MTM reimbursement rates would add beneficial profit-margin revenue to support compensation of a pharmacist or practitioner already working a shift in the clinic.

In-store medical clinics have proliferated, although growth has slowed recently. ${ }^{33}$ New clinics have opened in airports to meet the demand for travelers with chronic illness who cannot carry syringes that may be necessary for their medication because of heightened airport security and for airport employees who may require basic primary care services while at work. ${ }^{34}$ One 2007 study found 292 in-store clinics operated by 12 different companies/clinics in various chain stores across the country. ${ }^{31}$ According to our own search of company websites, 10 of the top 18 community pharmacy chains (determined by prescription sales figures $)^{35}$ housed 973 in-store health clinics in February 
2009 (Table 1). CVS stores provide the most clinics, with 545 Minute Clinics in 24 states. Walgreens was second with 326 clinics in 18 states.

\section{Employing a Prescriber: Potential Conflicts of Interest}

The nurse practitioners and physician assistants who usually staff an in-store medical clinic are able to write prescriptions in most states. ${ }^{36}$ These prescriptions may be easily filled within the same community pharmacy, creating a potential conflict of interest. Even among the array of plans and pricing details, the prescriber may understand that some prescription or over-thecounter drugs are most profitable for the store. Indeed, a report of interviews with in-store clinic operators found that a major motivation to open a clinic was the potential for increased traffic to the pharmacy. ${ }^{32}$

The American Medical Association has identified a potential conflict of interest concern with clinics located in pharmacies and other community stores. ${ }^{29}$ This recent trend presents a new "reversed ownership" scenario in which the pharmacies and community stores employ (in a sense "own") the salaried nurse practitioner/prescriber. In health care, self-referral or referral-for-profit (referral by a provider to organizations in which the provider has a financial interest) has presented a situation in which financial interests may dilute quality of care and increase costs..$^{37,38}$ Physician ownership of pharmacies was first restricted in 1989 under the first Ethics in Patient Referrals law sponsored by Representative Pete Stark (California), which proscribed patient referrals to a pharmacy owned by the physician. ${ }^{39}$ This law was updated in 1993, but evidence of over-utilization of services when financial incentives were present continued to emerge in certain areas of health care, such as radiology. ${ }^{40}$ The more specific and restrictive "Stark III" regulations were published in 2007. ${ }^{41}$

However, the scenario of financial interests presented by instore clinics has not been specifically anticipated by the rules. MTM reviews that occur in a clinic with a prescriber available may generate new prescriptions (or different, more profitable products) to be sold at the sales counter. Some in-store clinic patients could have particularly generous insurance that does not prevent steering them toward more costly products. Patients could also possibly be counseled to purchase medication when none would have sufficed. Or, the medication review could recommend replacing a prescription product with something available over-the-counter, which in some cases could boost store profits. Finally, because of economies of scale and ready availability of clinic space, large chain pharmacies that house in-store clinics operate at a competitive advantage over independent pharmacies in providing MTM.

\section{Conclusion}

The MMA 2003 mandate of MTM services within Part D plans will help further develop a practice that improves health, safety, and efficiency. These recent developments enhance the profession of pharmacy and its clinical cognitive services. The proximity of pharmacist and prescriber around an in-store clinic may even create a more desirable health care collaborative team approach, although more serious chronic conditions are not likely to be managed at a big retail store. At the same time, these trends have created a new and perhaps unanticipated conflict-of-interest situation to which the public sector should be alerted because large chain pharmacies now employ prescribers. In-store clinics have already attracted attention for possible conflicts of interest, but MTM services increase this potential because medication reviews may involve recommendations to make certain purchases. Meanwhile, at least 1 physician has responded to the proliferation of in-store clinics with a call for increased physician dispensing, without addressing the referral-for-profit problem. ${ }^{42}$

With respect to program evaluation, the availability of billing codes for pharmacists providing MTM means that data on utilization may exist but are made public only at the discretion of private companies and not by CMS. Claims data from Medicare Part D, only recently made publicly available for research purposes, do not specifically enumerate MTM.43 Future research should include thorough assessment of data, reviews of MTM eligibility and enrollment protocols, analysis of pharmacists and other providers within and without the community pharmacy setting, and more assessment of outcomes and results from the programs. Because MTM is obligatory in PDP contracts and not specifically tracked, important public health data may be left uncollected.

\section{Authors}

DANIEL M. COOK, PhD, is Assistant Professor of Health Policy, and ADEL MBURIA-MWALILI, MEd, MPH, is Research Associate, School of Community Health Sciences, University of Nevada-Reno, Reno, Nevada.

AUTHOR CORRESPONDENCE: Daniel M. Cook, PhD, Assistant Professor of Health Policy, School of Community Health Sciences, University of Nevada-Reno, Mailstop 274, Reno, NV 89557. Tel: 775.682.7095; Fax: 775.784.1340;E-mail:dmcook@unr.edu

\section{DISCLOSURES}

The authors report no financial or other conflicts of interest related to the subject of this commentary. Funding for this work was provided by the Gerontology Academic Program and Sanford Center for Aging at the University of Nevada-Reno.

Cook had primary responsibility for concept and design and for revision of the manuscript. Mburia-Mwalili had primary responsibility for data collection. Data interpretation was performed by Cook, with assistance from Mburia-Mwalili. Writing of the manuscript was the responsibility of both authors. 


\section{REFERENCES}

1. Manasse HR, Jr., Speedie MK. Pharmacists, pharmaceuticals, and policy issues shaping the work force in pharmacy. Am J Health Syst Pharm. 2007;64(12):e30-48

2. Gonzalez J, Noga M. Medication therapy management. J Manag Care Pharm. 2008;14(6, suppl S-c):S8-S1l. Available at: http://www.amcp.org/ data/jmcp/Aug\%20suppl\%20C_S8-S11.pdf.

3. Medicare Prescription Drug, Improvement, and Modernization Act of 2003. Public Law No. 108-173: December 8, 2003. Available at: http://www. ustreas.gov/offices/public-affairs/hsa/pdf/pl108-173.pdf. Accessed June 16, 2009

4. Isetts BJ, Buffington DE, Pharmacist Services Technical Advisory Coalition. CPT code-change proposal: national data on pharmacists' medication therapy management services. Am J Health Syst Pharm. 2007;64(15):1642-46.

5. Barnett MJ, Frank J, Wehring H, et al. Analysis of pharmacist-provided medication therapy management (MTM) services in community pharmacies over 7 years. J Manag Care Pharm. 2009;15(1):18-31. Available at: http:// www.amcp.org/data/jmcp/018-031.pdf

6. Bluml BM. Definition of medication therapy management: development of professionwide consensus. J Am Pharm Assoc (2003). 2005;45(5):566-72.

7. Bunting BA, Cranor CW. The Asheville Project: long-term clinical, humanistic, and economic outcomes of a community-based medication therapy management program for asthma. J Am Pharm Assoc (2003). 2006;46(2):133-47.

8. Stebbins MR, Kaufman DJ, Lipton HL. The PRICE clinic for low-income elderly: a managed care model for implementing pharmacist-directed services. J Manag Care Pharm. 2005;11(4):333-41. Available at: http://www.amcp. org/data/jmcp/contemporary_333_34l.pdf.

9. McLean DL, McAlister FA, Johnson JA, et al. A randomized trial of the effect of community pharmacist and nurse care on improving blood pressure management in patients with diabetes mellitus: study of cardiovascular risk intervention by pharmacists-hypertension (SCRIP-HTN). Arch Intern Med. 2008;168(21):2355-61

10. Altavela JL, Jones MK, Ritter M. A prospective trial of a clinical pharmacy intervention in a primary care practice in a capitated payment system. J Manag Care Pharm. 2008;14(9):831-43. Available at: http://www.amcp.org/ data/jmcp/831-843.pdf.

11. Nietert PJ, Tilley BC, Zhao W, et al. Two pharmacy interventions to improve refill persistence for chronic disease medications: a randomized, controlled trial. Med Care. 2009;47(1):32-40

12. Thompson CA. National billing codes announced for pharmacists' clinical services. Am J Health Syst Pharm. 2005;62(16):1640-42

13. Thompson CA. Pharmacists' CPT codes become permanent: next step is to set valuation for each code. Am J Health Syst Pharm. 2007;64(23):2410-12.

14. The Lewin Group. Medication therapy management services: a critical review. J Am Pharm Assoc (2003). 2005;45(5):580-87. Available at: http:// www.accp.com/docs/positions/commentaries/mtms.pdf. Accessed June 16, 2009

15. Kilian J, Stubbings J. Medicare Part D: Selected issues for pharmacists and beneficiaries in 2007. J Manag Care Pharm. 2007;13(1):59-65. Available at: http://www.amcp.org/data/jmcp/59-65.pdf

16. Touchette DR, Burns AL, Bough MA, Blackburn JC. Effective Health Care Research Report No. 1: Survey of Medicare Part D Plans' Medication Therapy Management Programs. (Prepared by University of Illinois-Chicago DEcIDE Center Under Contract No. HSA29020050038I.) Rockville MD: Agency for Healthcare Research and Quality; February 2007. Available at: http:// effectivehealthcare.ahrq.gov/repFiles/Medication_Therapy_Management_ Programs.pdf. Accessed June 12, 2009
17. Centers for Medicare \& Medicaid Services. Medicare Part D Medication Therapy Management (MTM) Programs: 2008 Fact Sheet. Available at: http://www.cms.hhs.gov/PrescriptionDrugCovContra/Downloads/ MTMFactSheet.pdf. Accessed June 12, 2009.

18. Brooks JM, Unni EJ, Klepser DG, Urmie JM, Farris KB, Doucette WR. Factors affecting demand among older adults for medication therapy management services. Res Social Adm Pharm. 2008;4(4):309-19.

19. Moczygemba LR, Barner JC, Gabrillo ER, Godley PJ. Development and implementation of a telephone medication therapy management program for Medicare beneficiaries. Am J Health Syst Pharm. 2008;65(17):1655-60.

20. Thompson CA. Minnesota pharmacists use CPT codes. Am J Health Syst Pharm. 2006;63(13):1208,1210.

21. Dole EJ, Murawski MM. Reimbursement for clinical services provided by pharmacists: what are we doing wrong? Am J Health Syst Pharm. 2007;64(1):104-06

22. Nutescu EA, Klotz RS. Basic terminology in obtaining reimbursement for pharmacists' cognitive services. Am J Health Syst Pharm. 2007;64(2):18692.

23. Moczygemba LR, Barner JC, Roberson K. Texas pharmacists' opinions about and plans for provision of medication therapy management services. $J$ Am Pharm Assoc (2003). 2008;48(1):38-45.

24. Beatty SJ, Rodis JL, Bellebaum KL, Mehta BH. Community and ambulatory pharmacy: evaluation of patient care services and billing patterns before implementation of Medicare part D. J Am Pharm Assoc (2003). 2006;46(6):707-14.

25. Urmie JM, Farris KB, Herbert KE. Pharmacy students' knowledge of the Medicare drug benefit and intention to provide Medicare medication therapy management services. Am J Pharm Educ. 2007;71(3):41.

26. Spooner JJ. A bleak future for independent community pharmacy under Medicare Part D. J Manag Care Pharm. 2008;14(9):878-81. Available at: http://www.amcp.org/data/jmcp/878-881.pdf.

27. Carroll NV. Estimating the impact of Medicare Part D on the profitability of independent community pharmacies. J Manag Care Pharm. 2008;14(8):768-79. Available at: http://www.amcp.org/data/jmcp/768-779. pdf.

28. Benner JS, Kocot SL. Medicare Part D: good for patients and an opportunity for pharmacists. J Manag Care Pharm. 2009;15(1):66-70. Available at: http://www.amcp.org/data/jmcp/066-070.pdf.

29. Sloane T. Another turf war. AMA campaign against retail clinics conflicts with the evidence. Mod Health. 2007;37(28):31.

30. Mehrotra A, Wang MC, Lave JR, Adams JL, McGlynn EA. Retail clinics, primary care physicians, and emergency departments: a comparison of patients' visits. Health Aff (Millwood). 2008;27(5):1272-82.

31. Bohmer R. The rise of in-store clinics-threat or opportunity? N Engl J Med. 2007;356(8):765-68.

32. Laws M, Scott MK. The emergence of retail-based clinics in the United States: early observations. Health Aff (Millwood). 2008;27(5):1293-98.

33. Costello D. A checkup for retail medicine. Health Aff (Millwood). 2008;27(5):1299-1303

34. Author not listed. Airport MD, pharmacies move into U.S. airports. USA Today. April 11, 2008. Available at: http://www.nursinglink.com/news/3185airport-md-pharmacies-move-into-us-airports. Accessed June 16, 2009.

35. Top 30 Retail Pharmacy Chains. Drug Store News. August 22, 2005. Available at: http://findarticles.com/p/articles/mi_m3374/is_10_27/ai_ n15341413. Accessed June 16, 2009

36. Cipher DJ, Hooker RS, Guerra P. Prescribing trends by nurse practitioners and physician assistants in the United States. J Am Acad Nurse Pract. 2006;18(6):291-96.

37. Hoffer GE. Physician-ownership in pharmacies and drug repackagers. Inquiry. 1975;12(1):26-36 
38. Manchikanti L, McMahon EB. Physician refer thyself: is Stark II, phase III the final voyage? Pain Physician. 2007;10(6):725-41.

39. Wilson CN. Physician-owned pharmacies under attack. Hosp Pharm. 1990;25(3):273-76.

40. Mitchell JM. The prevalence of physician self-referral arrangements after Stark II: evidence from advanced diagnostic imaging. Health Aff (Millwood). 2007;26(3):w415-w424.

41. Becker S, Lundeen R, Heinze G. CMS issues final Phase III Regulations-significant impact on physician-hospital and physician-driven relationships. Health Care Law Mon. 2007;2007(12):2-19.
42. Nystrom JS. Time to respond to in-store clinics. J Am Osteopath Assoc. 2008;108(2):52-53.

43. Department of Health and Human Services, Centers for Medicare \& Medicaid Services. Medicare Program; Medicare Part D Claims Data; Final Rule. In: Centers for Medicare \& Medicaid Services, ed. 42 CFR Part 423. Federal Register: NARA; 2008. Available at: http://www.cms.hhs.gov/ PrescriptionDrugCovGenIn/Downloads/PartDDataReg.pdf. Accessed June 16, 2009. 